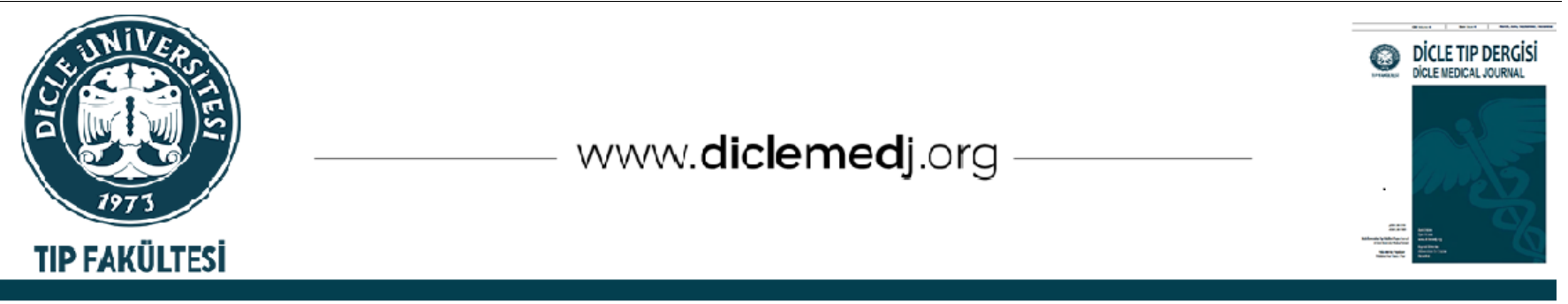

Özgün Araştırma / Original Article

\title{
CoVID-19 Geçiren Hastalarda Antikor Düzeylerinin Değerlendirilmesi
}

\author{
Özgür Aslan ${ }^{i}{ }_{1}$, Ayser Mızraklı ${ }^{\text {iD }}{ }_{2}$, Gülseren Samancı Aktar ${ }^{{ }^{D}}{ }_{2}$, Arzu Rahmanalı Onur ${ }^{D_{2}}$ \\ 1 Sağlık Bilimleri Üniversitesi Diyarbakır Gazi Yaşargil Eğitim ve Araștırma Hastanesi Merkez Laboratuvarı Tıbbi Biyokimya AD, \\ Kayapınar, Diyarbakır, Türkiye \\ 2 Sağlık Bilimleri Üniversitesi Diyarbakır Gazi Yaşargil Eğitim ve Araștırma Hastanesi Merkez Laboratuvarı Tıbbi Mikrobiyoloji AD. \\ Kayapınar, Diyarbakır, Türkiye
}

Geliş: 31.12.2020; Revizyon: 16.02.2021; Kabul Tarihi: 24.02.2021

Öz

Amaç: Ağır akut solunum sendromu korona virus 2 (SARS-CoV-2) hastalığı (COVID-19) halen büyük bir sorun olarak tüm dünyada etkisini göstermektedir. Halen SARS-CoV-2'ye karşı antikor tepkileri tam olarak anlaşlamamıștır ve serolojik testlerin klinik yararları belirsizdir. Bu çalışmada COVID-19 geçiren hastaların farklı zamanda alınmış numunelerde Roche SARS-CoV-2 antikor testi ile antikor düzeyleri değerlendirildi.

Yöntemler: Hastanemize 21 kişinin Mart 2020 - Nisan 2020 tarihleri arasındaki SARS-CoV-2 PCR testi bakılmış ve serum numunesi toplanmış kişilerden, Temmuz 2020 ayında tekrar numune alınmış ve toplam 42 numunede Roche SARS-CoV2 antikor düzeyleri bakılmıştır.

Bulgular: Toplam 21 kişinin ilk numunesinin 7'sinde Anti SARS CoV 2 antikorları negatif, 14'ünde Anti SARS CoV 2 antikorları pozitif olarak bulunmuştur. Negatif olan numunelerin hepsinde RT-PCR sonuçları pozitif olarak saptanmıștır. İkinci numunelerin 1'inde Anti SARS CoV 2 antikorları negatif, 20'isnde Anti SARS CoV 2 antikorları pozitif olarak bulunmuştur. Tüm kişilerin ikinci numuneleri ele alındığında, SARS-CoV-2 antikor değerlerinde hiçbir numunede düşüş saptanmamıştır.

Sonuç: Çalışmada ikinci numunelerde dahi antikor düzeyi negatif ve kısmen düşük cut off değerlerdeki numuneler bulunmaktadır. Bu çalışma gerek antikor düzeylerinin varlı̆̆ı ve takibi gerekse plazmaferezlerde donör antikor düzeyinin saptanması açısından önem taşımaktadır.

Anahtar kelimeler: SARS-CoV-2; COVID-19; immunoassay; serolojik testler, tanı testleri.

DOI: 10.5798/dicletip.887689

Correspondence / Yazışma Adresi: Özgür Aslan, Sağlık Bilimleri Üniversitesi Diyarbakır Gazi Yaşargil Eğitim ve Araştırma Hastanesi Merkez Laboratuvarı Üçkuyu Mh., 21010, Kayapınar, Diyarbakır, Türkiye e-mail: ozguraslan44@yahoo.com 


\section{Evaluation of Antibody Levels in Patients with COVID-19}

\section{Abstract}

Objective: Severe acute respiratory syndrome corona virus 2 (SARS-CoV-2) disease (COVID-19) is still showing its effect as a major problem all over the world. Currently, antibody responses to SARS-CoV-2 are not fully understood, and the clinical benefits of serological testing are uncertain. In this study, antibody levels of patients with COVID-19 were evaluated with Roche SARS-CoV-2 antibody test in samples taken at different times.

Method: SARS-CoV-2 PCR tests of 21 people were examined in our hospital between March 2020 and April 2020, and serum samples were collected again in July 2020 and Roche SARS-CoV-2 antibody levels were measured in a total of 42 samples.

Results: Anti SARS CoV 2 antibodies were found to be negative in 7 of the first samples of 21 people and Anti SARS CoV 2 antibodies were found to be positive in 14 of them. RT-PCR results were found to be positive in all of these 7 negative samples. Anti-SARS-CoV-2 antibodies were found to be negative in 1 of the second samples, and Anti-SARS-CoV-2 antibodies were found to be positive in 20 of them. Considering the second samples of all subjects, no decrease was detected in the SARS-CoV-2 antibody values in any sample.

Conclusions: In the study, there are samples with negative antibody levels and partially low cut off index values even in the second samples. This study is important in terms of both the presence and follow-up of antibody levels and detection of donor antibody levels in plasmapheresis.

Keywords: SARS-CoV-2; COVID-19; immunoassay; serological tests, diagnostic tests.

\section{GíRiş}

Çin'in Hubei Eyaleti, Wuhan Şehrinde ortaya çıkan ve tespit edilen ağır akut solunum sendromu korona virus 2 (SARS-CoV-2) hastalığı (COVID-19) ${ }^{1-3}$ halen büyük bir sorun olarak tüm dünyada etkisini göstermektedir. Dünya çapında COVID-19'lu toplam 82 milyon hasta sayısına ve 1.8 milyon ölüm sayılarına kadar ulaşmıştır ${ }^{4}$. SARS-CoV-2'nin doğru ve hızlı tanısı, COVID-19'lu hastaları zamanında izole etmek ve salgını durdurmak ve insanların hayatlarını kurtarmak için önemlidir. SARS-CoV2'nin hızlı bir şekilde tespiti için geliştirilen ve kullanılan gerçek zamanlı polimeraz zincir reaksiyonu (RT-PCR) testi viral nükleik asit tespiti ve COVID-19'un standart tanısı olarak kullanılmaktadır. Zaman alıcı, zahmetli ve özel ekipman gerektiren RT-PCR testi, özellikle kısıtlı laboratuvar koşulları olan bölgelerde kullanımını sinırlandırmıștır 2,5 .

Virüs enfeksiyonuna karşı gelişen insan antikor yanıtı, virüs enfeksiyonunun teşhisine yardımcı olmak için yaygın olarak kullanılmıştır. RT-PCR testleri ile karşılaştırıldığında, antikor düzeylerinin saptanması genellikle daha hızlı, ucuz, kullanımı kolay ve daha az laboratuvar profesyonelliği gerektirmesi açısından erişilebilirliği de daha kolaydır². Halen SARS-CoV-2'ye karşı antikor tepkileri tam olarak anlaşılamamıştır ve serolojik testlerin klinik yararları belirsizdir6.

Long ve arkadaşlarının yaptıkları çalışmada 164 kişiden maruziyetten $\sim 30$ gün sonra antikor testleri için serum numuneleri toplamışlardır. RT - PCR sonucu pozitif olan 16 vakanın hepsi virüse özgü IgG ve/veya IgM için pozitif çıkmıştır. Ayrıca, negatif RTPCR sonuçları olan 148 kişiden 7'sinde pozitif virüs spesifik IgG ve/veya IgM bulunmuştur, bu da yakın temaslıların \%4,3'ünün (7/164) RT - PCR testi ile kaçırıldığını göstermektedir6. Serokonversiyon IgM için semptomun başlangıcından sonra 5 gün içinde ve IgG için 5-7 gün içinde gözlenmiştir ${ }^{7,8}$. Maksimum serokonversiyon IgM için 2-3 haftada, IgG için 3-6 haftada gerçekleşir6-8. Testle ilgili çalışmaların testin yeni olması nedeniyle olmadığı ya da kısıtlı sayıda olduğu bilinmektedir.

Roche Anti SARS CoV 2, insan serumunda ve plazmasındaki SARS CoV 2 antikorlarının (IgG dahil) in vitro kantitatif tayinine yönelik bir immünolojik testtir. Bu testin SARS-CoV-2'ye karşı verilen immün yanıtının tayininde yardımcı olarak kullanılması amaçlanmıştır. Roche Elecsys Anti SARS CoV 2 testi SARS-CoV-2 antikorlarının tayininde nükleokapsid 182 
antijeni temsil eden bir rekombinant protein kullanir ${ }^{9}$.

Çalışmada hastanemizde COVID-19 geçiren hastaların farklı zamanda alınmış numunelerde Roche SARS-CoV-2 (Roche Diagnostics, Germany) antikor testi ile antikor düzeylerinin değerlendirilmesi amaçlanmıştır.

\section{YÖNTEMLER}

$\mathrm{Bu}$ çalışma Diyarbakır Gazi Yaşargil Eğitim ve Araştırma Hastanesi Etik Kurulu onayı ile gerçekleştirilmiştir (Tarih: 24.07.2020 ve Karar no: 520).

Hastanemize başvuran Mart 2020 - Nisan 2020 tarihleri arasındaki SARS-CoV-2 PCR testi bakılmış ve serum numunesi toplanmış kişilerden Temmuz 2020 ayında tekrar numune alınmış ve Roche SARSCoV-2 antikor düzeyleri bakılmıştır.

Çalışmaya 15'i kadın, 6'sı erkek olmak üzere 21 kişiden alınan 42 numune dahil edilmiştir. Kişilerin yaşı en düşük 25, en yüksek 41 ve ortalama 30,43 $\pm 3,59$ idi. Bu kişilerin ilk numunelerinden en az 36 gün sonra ikinci numunedeki antikor düzeyleri ölçülmüştür.

Çalışmalar için kan örnekleri rutin tüplere alındı, kan örneklerinin oda ısısında pıhtılaşması sonrası 1500 g'de santrifüj edilip, serum örnekleri ayrıldı ve örnekler $-80^{\circ} \mathrm{C}$ 'de çalışılıncaya kadar saklandı. Çalışma esnasında iyice çözülen serum örnekleri çalışıldı.

Çalışmadaki bütün örnekler rutin laboratuvarımızda kullanılan Roche cobas e 601 cihazinda (Roche Diagnostics, Germany) iki düzeyli kalite kontrol çalışıldıktan sonra orijinal kitleri ile yapıldı.

Roche cobas e 601 elde edilen örneklerin sonucu reaktif veya reaktif değil ve bunun yanı sıra cut off değeri (cut off indeks, COI) şeklinde verilir. Örneklerdeki COI $<1,0$ reaktif değil Anti SARS CoV 2 antikorları için negatif, COI $\geq 1,0$ reaktif Anti SARS CoV 2 antikorları için pozitif olarak yorumlanır.

Tablo I: SARS-CoV-2 RT PCR testi sonuçları

\begin{tabular}{|c|c|c|c|c|c|c|c|c|c|c|c|c|}
\hline \multirow[b]{2}{*}{ Kişi } & \multirow[b]{2}{*}{ Cinsiyet } & \multirow[b]{2}{*}{ Yaş } & \multicolumn{10}{|c|}{ SARS-CoV-2 RT-PCR } \\
\hline & & & Tarih* & Sonuç & Tarih* & Sonuç & Tarih* & Sonuç & Tarih* & Sonuç & Tarih* & Sonuç \\
\hline 1 & $\mathrm{~K}$ & 29 & 17.04 & Poz & 02.05 & Neg & 04.05 & Neg & & & & \\
\hline 2 & E & 29 & 21.04 & Poz & 30.04 & Neg & 02.05 & Neg & 28.05 & Neg & & \\
\hline 3 & E & 32 & 22.04 & Poz & 23.04 & Poz & 30.04 & Neg & 02.05 & Neg & & \\
\hline 4 & E & 31 & 21.04 & Poz & 30.04 & Neg & 02.05 & Neg & 27.05 & Neg & & \\
\hline 5 & $\mathrm{~K}$ & 31 & 23.04 & Poz & 01.05 & Neg & 04.05 & Neg & & & & \\
\hline 0 & $\mathrm{~K}$ & 33 & 22.04 & Poz & 01.05 & Neg & 04.05 & Neg & & & & \\
\hline 7 & $\mathrm{~K}$ & 29 & 18.04 & Poz & 25.04 & Neg & 27.04 & Neg & & & & \\
\hline 8 & E & 28 & 17.04 & Poz & 25.04 & Neg & 27.04 & Neg & & & & \\
\hline 9 & E & 28 & 25.04 & Neg & & & & & & & & \\
\hline 10 & $\mathrm{~K}$ & 28 & 27.04 & Neg & 07.05 & Neg & 08.05 & Neg & & & & \\
\hline 11 & $\mathrm{~K}$ & 33 & 08.05 & Poz & 14.05 & Neg & 21.05 & Neg & & & & \\
\hline 12 & $\mathrm{~K}$ & 27 & 30.04 & $\mathrm{Neg}$ & 08.05 & Neg & 11.05 & Neg & & & & \\
\hline 13 & $\mathrm{~K}$ & 33 & 01.05 & Poz & 11.05 & Neg & 14.05 & Neg & & & & \\
\hline 14 & $\mathrm{~K}$ & 41 & 27.04 & $\mathrm{Neg}$ & 01.05 & Poz & 11.05 & Neg & 14.05 & Neg & & \\
\hline 15 & $\mathrm{~K}$ & 25 & 17.04 & Poz & 26.04 & Neg & 28.04 & Neg & & & & \\
\hline 16 & $\mathrm{~K}$ & 32 & 22.04 & Poz & 30.04 & Neg & 02.05 & Poz & 05.05 & Neg & 07.05 & Neg \\
\hline 17 & $\mathrm{E}$ & 28 & 04.05 & Poz & 13.05 & Neg & 20.05 & Neg & & & & \\
\hline 18 & $\mathrm{~K}$ & 33 & 23.04 & Neg & 12.05 & Poz & 21.05 & Neg & 23.05 & Neg & & \\
\hline 19 & $\mathrm{~K}$ & 30 & 22.04 & Poz & 30.04 & Neg & 02.05 & Neg & & & & \\
\hline 20 & $\mathrm{~K}$ & 34 & 22.04 & Poz & 30.04 & Neg & 02.05 & Neg & 28.05 & Neg & & \\
\hline 21 & $\mathrm{~K}$ & 25 & 23.04 & Poz & 03.04 & Neg & 11.05 & Neg & & & & \\
\hline
\end{tabular}




\section{BULGULAR}

Çalışmaya 21 kişiden alınan toplam 42 numune dahil edilmiștir. Tüm hastalara en az 1 defa SARSCoV-2 RT PCR testi bakılmış olup 3 kişide RT PCR testi negatif saptanmıştır. Diğer numunelerin SARS-
CoV-2 RT PCR sonuçları en az bir kez pozitif olarak saptanmıştır (Tablo I). SARS-CoV-2 RT PCR sonucu negatif olan bu 3 kişide antikor düzeyleri her iki numunelerinde de pozitif olarak saptanmıştır (Tablo II).

Tablo II: Anti SARS CoV 2 antikor sonuçları

\begin{tabular}{|c|c|c|c|c|c|c|c|}
\hline Kişi & Cinsiyet & Yaş & $\begin{array}{l}\text { 1.numune } \\
\text { alma tarihi }\end{array}$ & $\begin{array}{l}\text { 1. numune Roche } \\
\text { Anti-SARS-CoV-2 } \\
\text { COI* değerleri }\end{array}$ & $\begin{array}{l}\text { 2. numune } \\
\text { alma tarihi }\end{array}$ & $\begin{array}{l}\text { 2. numune Roche } \\
\text { Anti-SARS-CoV-2 } \\
\text { COI* değerleri }\end{array}$ & $\begin{array}{c}\text { İki } \\
\text { numune } \\
\text { arası gün } \\
\text { farkı } \\
\end{array}$ \\
\hline 1 & $\mathrm{~K}$ & 29 & 22.04 .2020 & 49.41 & 30.06 .2020 & 123.100 & 70 \\
\hline 2 & E & 29 & 30.04 .2020 & 0.286 & 30.06 .2020 & 93.450 & 62 \\
\hline 3 & E & 32 & 30.04 .2020 & 0.584 & 30.06 .2020 & 71.740 & 62 \\
\hline 4 & E & 31 & 30.04 .2020 & 3.82 & 30.06 .2020 & 78.090 & 62 \\
\hline 5 & $\mathrm{~K}$ & 31 & 04.05 .2020 & 0.282 & 15.07 .2020 & 22.800 & 72 \\
\hline 0 & K & 33 & 04.05 .2020 & 0.13 & 15.07.2020 & 0.806 & 72 \\
\hline 7 & $\mathrm{~K}$ & 29 & 06.05 .2020 & 0.852 & 30.06 .2020 & 4.030 & 55 \\
\hline 8 & E & 28 & 06.05 .2020 & 7.78 & 30.06 .2020 & 12.850 & 55 \\
\hline 9 & $\mathrm{E}$ & 28 & 07.05 .2020 & 22.02 & 10.07.202 & 32.580 & 64 \\
\hline 10 & K & 28 & 07.05 .2020 & 7.36 & 05.07 .2013 & 16.380 & 69 \\
\hline 11 & $\mathrm{~K}$ & 33 & 08.05 .2020 & 1.12 & 05.07 .2013 & 38.500 & 68 \\
\hline 12 & $\mathrm{~K}$ & 27 & 08.05 .2020 & 17.19 & 30.06 .2020 & 108.400 & 53 \\
\hline 13 & $\mathrm{~K}$ & 33 & 11.05 .2020 & 4.64 & 30.06 .2020 & 34.900 & 50 \\
\hline 14 & $\mathrm{~K}$ & 41 & 11.05 .2020 & 6.13 & 30.06 .2020 & 55.960 & 50 \\
\hline 15 & $\mathrm{~K}$ & 25 & 12.05 .2020 & 4.57 & 17.07 .2020 & 17.140 & 66 \\
\hline 16 & $\mathrm{~K}$ & 32 & 19.05.2020 & 32.41 & 30.06 .2020 & 58.360 & 42 \\
\hline 17 & $\mathrm{E}$ & 28 & 20.05 .2020 & 5.86 & 30.06 .2020 & 20.750 & 41 \\
\hline 18 & $\mathrm{~K}$ & 33 & 21.05 .2020 & 0.126 & 03.07.2020 & 1.110 & 43 \\
\hline 19 & $\mathrm{~K}$ & 30 & 27.05 .2020 & 0.38 & 03.07.2020 & 1.770 & 37 \\
\hline 20 & $\mathrm{~K}$ & 34 & 28.05 .2020 & 8.12 & 03.07.2020 & 20.910 & 36 \\
\hline 21 & $\mathrm{~K}$ & 25 & 28.05 .2020 & 41.67 & 03.07.2020 & 65.340 & 36 \\
\hline
\end{tabular}

${ }^{*}$ COI= Cut off indeks: $\mathrm{COI}<1,0$ Anti SARS CoV 2 antikorları için negatif, COI $\geq 1,0$ Anti SARS CoV 2 antikorları için pozitif değerleri ifade eder.

Anti SARS CoV 2 antikorları için numune alma tarihleri ve sonuçlar Tablo II'de gösterilmektedir. İlk 21 numuneden 7'sinde Anti SARS CoV 2 antikorları negatif, 14'ünde Anti SARS CoV 2 antikorları pozitif olarak bulunmuştur. İkinci 21 numuneden 1'inde e Anti SARS CoV 2 antikorları negatif, 20'sinde
Anti SARS CoV 2 antikorları pozitif olarak bulunmuştur. İlk numunelerden 7'sindeki Anti SARS CoV 2 antikorları negatif olan hastalardan ikinci numunelerin 1'inde negatif COI (0.806), 2 numune düşük COI $(1.11,1.77)$ değerlerinde pozitif olduğu saptanmıștır (Tablo II). Tüm COI değerleri ikinci numunelerde daha yüksek saptanmıştır. 


\section{TARTIŞMA}

Çalışma hastanemizde Covid 19 geçirmiş olan 21 hastadan 42 numune alınarak yapılmıştır. SARS-CoV-2'nin hızlı bir şekilde tespiti için RTPCR testi kullanılmaktadır. SARS-CoV-2'nin bulaş sonrası antikor yanıtının oluşumu ve antikorların stabilliği konusunda çok fazla çalışma bulunmamaktadır. Çalışılan SARS-CoV2 (Roche Diagnostics, Germany) antikor testi total antikor düzeylerini belirlemekte olup viral spesifik IgM ve IgG ayrımı yapmamaktadır.

İlk numunelerde 7 numunede Anti SARS CoV 2 antikorları negatif, 14 numunede Anti SARS CoV 2 antikorları pozitif bulunmuştur. $\mathrm{Bu} 7$ numunenin hepsinde RT-PCR testi pozitif olmakla beraber PCR pozitifliği ile numune alma zamanı arasında en az 8 en fazla 36 gün bulunmaktaydı. Long ve arkadaşlarının yaptıkları çalışmada semptom başlangıcından yaklaşık 17-19 gün sonra virüse özgü pozitif IgG'li hastaların oranı \%100 iken semptom başlangıcından yaklaşık 20-22 gün sonra virüse özgü IgM'si pozitif hastaların oranı \%94,1'lik bir zirveye ulaştığını bildirmişlerdir6.

$\mathrm{Bu}$ çalışmadaki ikinci numunelerin 1'inde Anti SARS CoV 2 antikorları negatif, 20'sinde Anti SARS CoV 2 antikorları pozitif olarak bulunmuştur. $\mathrm{Bu}$ negatif numunedeki RT-PCR testi pozitiflik zamanı ile numune alma zamanı arasında 72 gün bulunmaktaydı. İlk numunede Anti SARS CoV 2 antikorları negatif olan 7 hastanın ikinci numunelerinin sadece 1'inde negatif olarak bulunmuş, 2 numune ise düşük COI $(1.11,1.77)$ değerlerde pozitif olduğu saptanmıştır. Diğer numunelerde en düşük COI değerleri 4.030 iken en yüksek COI değeri 123.100 olarak saptanmıştır. Bu durum 1 hastada antikor oluşmadığını göstermektedir.

Ağır akut solunum sendromu epidemisinden elde edilen veriler, viral spesifik IgM ve IgG içeren serolojik yanıtların, serolojik tanı için yeterli olduğunu göstermektedir ${ }^{10,11}$. Bu çalışmaların sonucundaki veriler ELISA testlerinin, SARS-CoV pnömonisinin serolojik teşhisi için daha az emek gerektirdiği ve testin hassas olduğu, çok daha ekonomik ve aynı zamanda viral kültüvasyon gerektirmediği için avantaj sağladığını belirtmişlerdir ${ }^{11}$.

RT-PCR testi negatif 3 kişi saptanmış olmakla beraber bu 3 kişinin hepsinde antikor testi hem ilk hem ikinci numunede pozitif olarak saptanmıștır. Wang ve arkadaşlarının yaptıkları çalışmada SARS-CoV-2 RNA için nasofarengiyal sürüntü örnekleri için $\% 63$, orofarengiyal sürüntü örnekleri için \%32 pozitiflik oranı saptamışlardır ${ }^{11}$. Çalışmadaki RT-PCR negatifliğinin numune ilişkili pozitiflik oranları veya numune alım zamanına bağlı olduğu düşünülmüştür.

Tüm kişilerin birinci ve ikinci numuneleri ele alındığında Anti SARS $\mathrm{CoV} 2$ antikor COI değerlerinde hiçbir numunede düşüş saptanmadı ve Anti SARS CoV 2 antikor negatif olan bir numunenin COI değeri ise 0.13'den 0.806 değerlerine yükseldiği saptandı.

COVID-19 tedavisi için geleneksel plazma tedavisi virolojik ve klinik özellikler açısından SARS, MERS ve COVID-19 arasında benzerlik olduğundan umut verici bir tedavi seçeneği olabilir ${ }^{13,14}$. Bu nedenle de antikor yanitlarının oluşumu ve stabilliği önem kazanmaktadır. Çalışmamızda ikinci numunelerde dahi antikor düzeyi negatif ve kısmen düşük COI değerindeki numuneler bulunmaktadır. $\mathrm{Bu}$ nedenle donörlerden alınacak plazmaların tedavi etkinliği açısından donörlerde antikor düzeylerinin bakılması çok önemli olduğunu düşünmekteyiz. Seghatchian ve Lanza plazma donörlerde diğer birçok teste ilaveten SARSCoV-2 antikorlarının bakılması gerektiğini bildirmișlerdir ${ }^{15}$.

$\mathrm{Bu}$ çalışmada kişi sayısının az olması ve serokonversiyon takibi açısından periyodik numune alımının gerekliliği sinırlılık olarak söylenebilir. Fakat gerek Covid 19 pandemi süreci ve gerekse kişi katılım zorluğu açısından 
çalışma kısıtlı kalmıştır. Yine de bu çalışmada aynı kişilerden iki farklı zamanda alınan örneklerde antikor düzeylerine bakılması ve ülkemizde antikor düzeyleri ile ilgili çalışmaların kısıtlı olması açısından önemlidir.

Sonuç olarak serolojik testler virüse maruz kalmış bireylerin belirlenmesi ve popülasyonun maruziyet oranını değerlendirilmesi için kullanılabilir. Serolojik testlerin nispeten kolay uygulanabilir olması nedeniyle daha fazla ve hızlı çalışma olanağı sağlar ve böylece toplumsal karar verme süreçlerde hızlı tedbirler almak için yardımcı olabilirler. Ayrıca Anti SARS CoV 2 antikorlarının immunoassay otomatize sistemlerde çalışılması çok yenidir. $\mathrm{Bu}$ çalışma gerek antikor düzeylerinin varlığı ve takibi gerekse plazmaferezlerde donör antikor düzeyinin saptanmasının gerekli olduğu durumlar açısından önem taşımaktadır.

Teşekkür: Roche SARS-CoV2 antikor testi temini için Diyar-Med Sağlık Ürünleri San. Tic. Ltd. Şti.'ye teşekkür ederiz.

Etik Kurul Kararı: Bu çalışma Diyarbakır Gazi Yaşargil Eğitim ve Araştırma Hastanesi Etik Kurulu onayı ile gerçekleştirilmiştir (Tarih: 24.07.2020 ve Karar no:520).

Çıkar Çatışması Beyanı: Yazarlar çıkar çatışması olmadığını bildirmişlerdir.

Finansal Destek: Bu çalışma her hangi bir fon tarafından desteklenmemiştir.

Declaration of Conflicting Interests: The authors declare that they have no conflict of interest.

Financial Disclosure: No financial support was received.

\section{KAYNAKLAR}

1. Singhal T. A Review of Coronavirus Disease-2019 (COVID-19). The Indian Journal of Pediatrics. 2020; 87: 281-6.

2. Şit D, Kayabaşı H. SARS-CoV-2 ile İlişskili Akut Böbrek Hasarı. Dicle Tip Dergisi. 2020; 47: 498-507.
3. Xiang F, Wang X, He X, et al. Antibody Detection and Dynamic Characteristics in Patients with COVID-19. Clin Infect Dis. 2020: ciaa461.

4. https://covid19.who.int/. WHO Coronavirus Disease (COVID-19) Dashboard 2020

5. Tang Y-W, Schmitz JE, Persing DH, Stratton CW. Laboratory Diagnosis of COVID-19: Current Issues and Challenges. 2020; 58: e00512-20.

6. Long Q-X, Liu B-Z, Deng H-J, et al. Antibody responses to SARS-CoV-2 in patients with COVID-19. Nature Medicine. 2020; 26: 845-8.

7. Liu W, Liu L, Kou G, et al. Evaluation of Nucleocapsid and Spike Protein-Based Enzyme-Linked Immunosorbent Assays for Detecting Antibodies against SARS-CoV-2. Journal of clinical microbiology. 2020; 58: e00461-20.

8. To KK-W, Tsang OT-Y, Leung W-S, et al. Temporal profiles of viral load in posterior oropharyngeal saliva samples and serum antibody responses during infection by SARS-CoV-2: an observational cohort study. The Lancet Infectious Diseases. 2020; 20: 56574.

9. Roche. Elecsys Anti-SARS-CoV-2 09203079500V Cobas system kit prospectus. In: Roche, editor. 2020.

10. Louie JK, Hacker JK, Mark J, et al. SARS and common viral infections. Emerg Infect Dis. 2004; 10: 1143-6.

11. Woo PC, Lau SK, Wong BH, et al. Detection of specific antibodies to severe acute respiratory syndrome (SARS) coronavirus nucleocapsid protein for serodiagnosis of SARS coronavirus pneumonia. Journal of clinical microbiology. 2004; 42: 2306-9.

12. Wang W, Xu Y, Gao R, , et al. Detection of SARS-CoV2 in Different Types of Clinical Specimens. JAMA. 2020; 323: 1843-4.

13. Chen L, Xiong J, Bao L, Shi Y. Convalescent plasma as a potential therapy for COVID-19. The Lancet Infectious diseases. 2020; 20: 398-400.

14. Duan K, Liu B, Li C, et al. The feasibility of convalescent plasma therapy in severe COVID-19 patients: a pilot study. 2020: 2020.03.16.20036145.

15. Seghatchian J, Lanza F. Convalescent plasma, an apheresis research project targeting and motivating the fully recovered COVID 19 patients: A rousing message of clinical benefit to both donors and recipients alike. Transfus Apher Sci. 2020; 59: 102794. 